\title{
Presença da Literatura Afro- Brasileira em Livros Didáticos de Ensino Médio
}

Márcia Froeblich*

Resumo: Este artigo expõe os resultados preliminares de um projeto de pesquisa que objetiva verificar e analisar a presença da literatura afro-brasileira em livros didáticos de Língua Portuguesa e Literatura Brasileira do Ensino Médio aprovados para o PNLD 2012.

Palavras-chave: Literatura Afro-Brasileira; Livros Didáticos; Ensino Médio.

Abstract: This paper presents preliminary results from a research which intends to verify and to analyze how Afro-Brazilian authors are presented in Portuguese and Brazilian Literature Textbooks for High School which were approved to be included in PNLD 2012.

Keywords: Afro-Brazilian literature; Textbooks; High School.

* Professora da Coordenadoria de Linguagens, Códigos e suas Tecnologias do Instituto Federal Sul-Rio-Grandense (IFSul) - Campus Pelotas. Mestre em Letras pela UFSM. E-mail: marcia_froe@hotmail.com 


\section{Introdução}

Este texto diz respeito a um projeto de pesquisa cujo propósito é verificar e analisar a presença da literatura afro-brasileira em livros didáticos de Língua Portuguesa e Literatura Brasileira destinados ao Ensino Médio. Como critério de seleção do corpus, determinou-se o exame das obras participantes do PNLD 2012 (Programa Nacional do Livro Didático), as quais, portanto, receberam avaliação positiva do MEC.

A Lei 10.639, de 9 de janeiro de 2003, alterou a Lei de Diretrizes e Bases da Educação Nacional incluindo a obrigatoriedade do ensino da História e Cultura Afro-Brasileira nos currículos da educação básica. Sendo a língua e a literatura elementos constituintes e constituídos pela cultura, tal determinação legal exige modificações no currículo das disciplinas de Língua Portuguesa e Literatura Brasileira. Assim, o presente projeto nasceu da necessidade de se examinar os manuais didáticos disponíveis aos públicos docente e discente do Ensino Médio a fim de avaliar sua adequação e profundidade no tratamento da produção literária afro-brasileira. Para tanto, o projeto pretende, a partir de subsídios teóricos dos estudos que tratam de questões como cultura, identidade e literatura afro-brasileira, proceder à análise da sua apresentação nos livros didáticos participantes do PNLD 2012.

\section{Currículo e Literatura Afro-Brasileira}

Antes de mais, é importante traçar as relações entre currículo e produção literária afro-brasileira. Segundo Tomaz Tadeu da Silva (2005), a teorização crítica sobre currículo concentrou-se, inicialmente, na análise das relações entre as diferentes classes sociais. Com o advento das teorias pós-críticas, tal análise sofreu um deslocamento, procurando incluir também as desigualdades educacionais centradas nas relações de gênero, raça e etnia. 
Historicamente, essa transformação apresentou duas fases. Primeiramente, as teorias focadas na dinâmica da raça e da etnia concentraram-se em questões de acesso à educação e ao currículo. Ou seja, buscava-se investigar os fatores responsáveis pelas altas taxas de fracasso escolar de crianças e jovens pertencentes a grupos étnicos e raciais minoritários. Os componentes curriculares, entretanto, não eram questionados (SILVA, 2005, p. 99)

Com o desenvolvimento do Pós-Estruturalismo e dos Estudos Culturais, deu-se início a uma segunda fase, na qual o "currículo passou a ser problematizado como sendo racialmente enviesado" (SILVA, 2005, p. 99), para, a seguir, os próprios conceitos de raça e etnia passarem por um processo de reflexão. $\mathrm{Na}$ visão pós-estruturalista, perspectiva dominante na teorização social contemporânea sobre raça e etnia, tais conceitos não podem ser considerados como construtos culturais fixos, dados, definitivamente estabelecidos, pois a identidade "é um processo de construção de sentido, a partir de um atributo cultural, ou de um conjunto coerente de atributos culturais, que recebe prioridade sobre as outras fontes" (CASTELLS apud MUNANGA, 2006, p. 19). A construção da identidade é pois dependente de um processo histórico e discursivo de construção da diferença e, portanto, está sujeita a um constante processo de mudança e transformação.

Da perspectiva histórica, conforme Silva (2005), a identidade étnica e racial sempre foi uma questão de saber e poder, pois está intimamente vinculada às relações de poder que opõem e opuseram o homem branco europeu aos povos das regiôes por ele colonizados. E é justamente por meio do elo entre conhecimento, identidade e poder que os temas da raça e da etnia têm seu lugar nas teorias do currículo. De acordo com Silva (2005):

O texto curricular, entendido aqui de forma ampla - o livro didático e paradidático, as lições orais, as orientações curriculares oficiais, os rituais escolares, as datas festivas e comemorativas - está recheado de narrativas nacionais, étnicas e raciais. Em geral, essas narrativas celebram os mitos da origem nacional, confirmam o privilégio das identidades dominantes e tratam as identidades dominadas como exóticas ou folclóricas. Em 
termos de representação racial, o texto curricular conserva, de forma evidente, as marcas da herança colonial. [...] A questão torna-se, então: como desconstruir o texto racial do currículo, como questionar as narrativas hegemônicas de identidade que constituem o currículo? (p. 101-102)

Cabe aqui conduzir essa discussão sobre currículo para o âmbito específico da disciplina enfocada por este projeto, a Literatura Brasileira. Embora presente no currículo desde o Ensino Fundamental, é no nível médio que a literatura se disciplinariza e, como tal, os alunos passam a estudá-la de modo sistemático. Tal como ocorreu em outras áreas do conhecimento, o estudo da Literatura, e as disciplinas a ela associadas (História da Literatura, Sociologia da Literatura), também sofreu mudanças sob o influxo de movimentos teóricos como os já citados Pós-Estruturalismo e Estudos Culturais e também o Pós-Colonialismo, o qual tem como objetivo analisar o complexo das relaçôes de poder entre as diferentes nações que compõem a herança econômica, política e cultural da conquista colonial europeia.

No que tange às questões identitárias, essas teorias, aliadas ao feminismo e às teorizações baseadas em outros movimentos sociais, promoveram a problematização dos currículos centrados no cânone literário - entendido como o conjunto de obras de 'elevada' qualidade estética. Nesse sentido, lutaram pela inserção de formas culturais que refletissem a experiência de grupos cujas identidades culturais e sociais são marginalizadas pela identidade dominante: masculina, branca e eurocêntrica. É nesse contexto que, no Brasil, a produção literária afro-brasileira passou a receber atenção por parte de estudiosos e sua inclusão nos currículos escolares passou a ser reivindicada por pesquisadores e pelo movimento negro.

Tal movimento reivindicatório culminou, em 2003, com a promulgação, pelo Presidente da República, da Lei 10.639, a qual determina a obrigatoriedade, nos estabelecimentos de ensino fundamental e médio, oficiais e particulares, do ensino sobre História e Cultura Afro-Brasileira. O texto legal faz menção especial à disciplina de Literatura: "Os conteúdos referentes à 
História e Cultura Afro-Brasileira serão ministrados no âmbito de todo o currículo escolar, em especial nas áreas de Educação Artística e de Literatura e História Brasileiras” (BRASIL, 2003).

Para que a literatura afro-brasileira possa, efetivamente, ser integrada ao currículo da disciplina de Literatura Brasileira, é preciso, porém, esclarecer, à luz dos estudos que abordam o tema, o que se entende por literatura afro-brasileira, outrora denominada literatura negra. Uma distinção entre tais termos se faz necessária:

A expressão 'literatura negra', presente em antologias literárias publicadas em vários países, está ligada a discussões no interior de movimentos que surgiram nos Estados Unidos e no Caribe, espalharam-se por outros espaços e incentivaram um tipo de literatura que assumia as questões relativas à identidade e às culturas dos povos africanos e afro-descendentes [sic]. Através do reconhecimento e revalorização da herança cultural africana e da cultura popular, a escrita literária é assumida e utilizada para expressar um novo modo de se conceber o mundo (SOUZA; LIMA, 2006, p. 11-12).

Desse modo, o termo guarda uma acepção internacionalizada que se buscou restringir com a adoção de literatura afrobrasileira, a qual se limita à produção literária de afrodescendentes de um espaço geográfico definido, no caso, o Brasil. Mais do que isso, a expressão literatura afro-brasileira "procura assumir as ligações entre o ato criativo que o termo 'literatura' indica e a relação dessa criação com a África, seja aquela que nos legou a imensidão de escravos trazida para as Américas, seja a África venerada como berço da civilização" (SOUZA; LIMA, 2006, p. 24).

Uma das pioneiras do estudo da literatura afro-brasileira, a professora Zilá Bernd, a define como "sendo aquela onde emerge uma consciência negra, ou seja, onde um 'eu' enunciador assume uma identidade negra, buscando recuperar as raízes da cultura afro-brasileira e preocupando-se em protestar contra o racismo e o preconceito de que é vítima até hoje a comunidade negra brasileira” (1998, p. 91). Trata-se de uma definição que privilegia, conforme informa Eduardo de Assis Duarte, o ponto de vista enunciativo, mais especificamente, o grau de adesão a 
uma "visão de mundo identificada à história, cultura, logo a toda problemática inerente à vida desse importante segmento da população" (DUARTE, 2010, p. 2)

No entanto, para se construir um conceito mais completo do que caracteriza tal produção (e a diferencia das demais que compõem a literatura brasileira), há que se considerar também outros fatores comumente elencados quando se depara com a discussão sobre a 'natureza' da literatura afro-brasileira. Para Duarte (2010), os fatores seriam os seguintes:

- Temática - esse aspecto abarcaria diferentes vertentes, podendo contemplar o resgate da história do povo negro na diáspora brasileira, passando pela denúncia da escravidão e de suas consequências ou ir até a glorificação de heróis como Zumbi e Ganga Zumba. Também poderia abranger as tradições culturais ou religiosas transplantadas para o território brasileiro, destacando a riqueza dos mitos, lendas e de todo um imaginário circunscrito muitas vezes à oralidade. Outra vertente dessa diversidade temática se situaria na contemporaneidade brasileira, buscando denunciar ao leitor os dramas vividos pelos indivíduos afrodescendentes, como a desigualdade social, a exclusão e o preconceito;

- Autoria - fator extralinguístico, que vincula a produção a um autor afrodescendente, tendo o cuidado de "se atentar para a abertura implícita ao sentido da expressão, a fim de abarcar as individualidades muitas vezes fraturadas oriundas do processo miscigenador" (DUARTE, 2010, p. 2);

- Ponto de vista - já exposto acima;

- Linguagem - aspecto que identificaria nessa produção a constituição de uma discursividade específica, caracterizada pela expressão de ritmos e significados novos, incluindo ainda um vocabulário relacionado às práticas linguísticas oriundas de África e inseridas no processo transculturador em curso no Brasil;

- Público-leitor - o estudioso assinala ainda a formação de um público-leitor afrodescendente como fator de intencionalidade próprio a essa literatura e, portanto, ausente do projeto norteador do restante da produção literária brasileira. 
Assim sendo, a literatura afro-brasileira constitui-se como parte da literatura brasileira, mas, ao mesmo tempo, relaciona-se estreitamente a questões culturais e identitárias de um segmento social específico historicamente vinculado ao continente africano. Caracteriza-se também como literatura engajada, ao dar voz a setores marginalizados pela sociedade, mas que busca ainda contribuir para a construção, no âmbito da cultura letrada, de uma dicção discursiva própria dos afrodescendentes. É dessa produção que se pretende verificar a presença nos livros didáticos de Língua Portuguesa e Literatura Brasileira destinados ao Ensino Médio para, a seguir, efetuar a análise dos conteúdos neles apresentados.

\section{Resultados Preliminares}

Após a realização das etapas de revisão bibliográfica e seleção do corpus, foi efetuado o levantamento da presença da literatura afro-brasileira nos livros didáticos de 10 (dez) das 11 (onze) coleções aprovadas para o PNLD 2012 (a coleção Ser Protagonista Português, da SM Edições, não foi disponibilizada pela editora para análise). No momento, já se iniciou a análise dos dados obtidos no levantamento ao mesmo tempo em que ele está sendo revisado. Por essa razão, esta seção apresenta os resultados preliminares obtidos do levantamento.

Para a análise dos dados, verificou-se a necessidade de criar algumas categorias. A primeira engloba os autores afrodescendentes canônicos - Cruz e Sousa, Machado de Assis e Lima Barreto -, os quais são contemplados em todas as coleções, em geral nos capítulos e/ou seçôes que abordam os períodos literários a que eles pertencem (Simbolismo, Realismo e Pré-Modernismo), por isso costumam aparecer mais fortemente no volume 2 das coleções. Os dois primeiros têm presença mais destacada, pois são considerados os principais expoentes dos estilos literários dos quais fazem parte, mas nem sempre, sobretudo no que diz respeito a Machado de Assis, há informaçốes sobre como a temática afro-brasileira foi explorada nas obras desses autores. 
Mais comum é a menção à afrodescendência nas informações biográficas. Já no caso de Cruz e Sousa, busca-se, em alguns casos, desmentir a concepção corrente de que, em sua obra, não se perceberia uma voz enunciativa de consciência negra.

Autores afrodescendentes resgatados do passado pela crítica especializada foram agrupados em outra categoria (vide Tabela 1). O rol de autores revela algumas ausências, como, por exemplo, dos poetas Gonçalves Crespo e B. Lopes, os quais não são citados em nenhuma coleção. Entre os autores citados, predominam os poetas, pois apenas Maria Firmina dos Reis dedicou-se à narrativa. Em relação ao estilo de época, com exceção de Domingos Caldas Barbosa, todos os demais pertencem ao Romantismo. $\mathrm{O}$ autor mais referenciado é Luís Gama.

Tabela 1 - Autores afrodescendentes resgatados do passado.

\begin{tabular}{|c|c|}
\hline Autores Afrodescendentes & Coleções que os citam \\
\hline Auta de Souza (* 1876 - + 1901) & $\begin{array}{l}\text { Projeto Eco - Lingua Portuguesa } \\
\text { v. } 2\end{array}$ \\
\hline $\begin{array}{l}\text { Domingos Caldas Barbosa } \\
\left({ }^{*} 1739-+1800\right)\end{array}$ & $\begin{array}{l}\text { Projeto Eco - Língua Portuguesa } \\
\text { v. } 1\end{array}$ \\
\hline Luís Gama (* $1830-+1882)$ & $\begin{array}{l}\text { Projeto Eco - Lingua Portuguesa } \\
3 \text { vols. }\end{array}$ \\
\hline $\begin{array}{l}\text { Maria Firmina dos Reis } \\
\left({ }^{*} 1825-+1917\right)\end{array}$ & $\begin{array}{l}\text { Português - Literatura, Gramá- } \\
\text { tica, Produção de Texto v. } 2 \\
\text { Projeto Eco - Lingua Portuguesa } \\
\text { v. } 2 \\
\text { Português - Literatura, Gramá- } \\
\text { tica, Produção de Texto v. } 2\end{array}$ \\
\hline $\begin{array}{l}\text { Trajano Galvão } \\
\left(*^{*} 1830-+1864\right)\end{array}$ & $\begin{array}{l}\text { Português - Literatura, Gramá- } \\
\text { tica, Produção de Texto v. } 2\end{array}$ \\
\hline
\end{tabular}

Apenas 2 coleções contemplam esses autores: Projeto Eco - Lingua Portuguesa - em seus 3 volumes - (Editora Positivo) e Português - Literatura, Gramática, Produção de Texto (Editora 
Moderna), no segundo volume, o qual aborda o período romântico. A primeira tem uma proposta diferenciada, buscando, desde o primeiro volume, abordar a literatura através de uma perspectiva que privilegia a africanidade e a afrobrasilidade. Isso revela um cuidado especial na elaboração do texto, tendo em vista atender ao estipulado pela Lei 10.639/2003 Quanto à segunda, a preocupação em trazer autores marginais à História da Literatura tradicional é mencionada na avaliação do Guia de livros didáticos (2011):

As temáticas selecionadas propiciam a reflexão sobre a condição humana, as injustiças e os preconceitos, entre outros importantes temas. Observa-se, também, a inclusão de autores e obras que rompem, em certa medida, com uma visão cristalizada da literatura, como se vê na referência a mulheres autoras e à literatura popular [...] (p. 47).

A terceira categoria abrange os autores afrodescendentes contemporâneos (isto é, aqueles com produção a partir do Modernismo) e é a categoria com maior número de autores (vide Tabela 2).

Tabela 2 - Autores afrodescendentes contemporâneos

\begin{tabular}{|c|c|}
\hline Autores Afrodescendentes & Coleções que os citam \\
\hline $\begin{array}{l}\text { Abdias do Nascimento }(* 1914 \\
-+2011)\end{array}$ & $\begin{array}{l}\text { Projeto Eco - Lingua Portuguesa } \\
\text { v. } 3\end{array}$ \\
\hline Adão Ventura $\left({ }^{*} 1946-+2004\right)$ & Português Linguagens v. 2 \\
\hline Allan da Rosa $(* 1976)$ & $\begin{array}{l}\text { Projeto Eco - Lingua Portuguesa } \\
\text { v. } 3\end{array}$ \\
\hline Carlos de Assumpção ( * 1927) & $\begin{array}{l}\text { Novas Palavras v. } 3 \\
\text { Português - Literatura, Gramáti- } \\
\text { ca, Produção de Texto v.1 }\end{array}$ \\
\hline $\begin{array}{l}\text { Carolina Maria de Jesus }(* 1914 \\
-+1977)\end{array}$ & $\begin{array}{l}\text { Português-Contexto, interlocução } \\
\text { e sentido v. } 1 \text { e } 2 \\
\text { Lingua Portuguesa-Linguagem e } \\
\text { Interação v. } 1\end{array}$ \\
\hline Cuti (Luiz Silva) $\left(^{*}\right.$ 1951) & $\begin{array}{l}\text { Projeto Eco - Lingua Portuguesa } \\
\text { v. } 2\end{array}$ \\
\hline
\end{tabular}




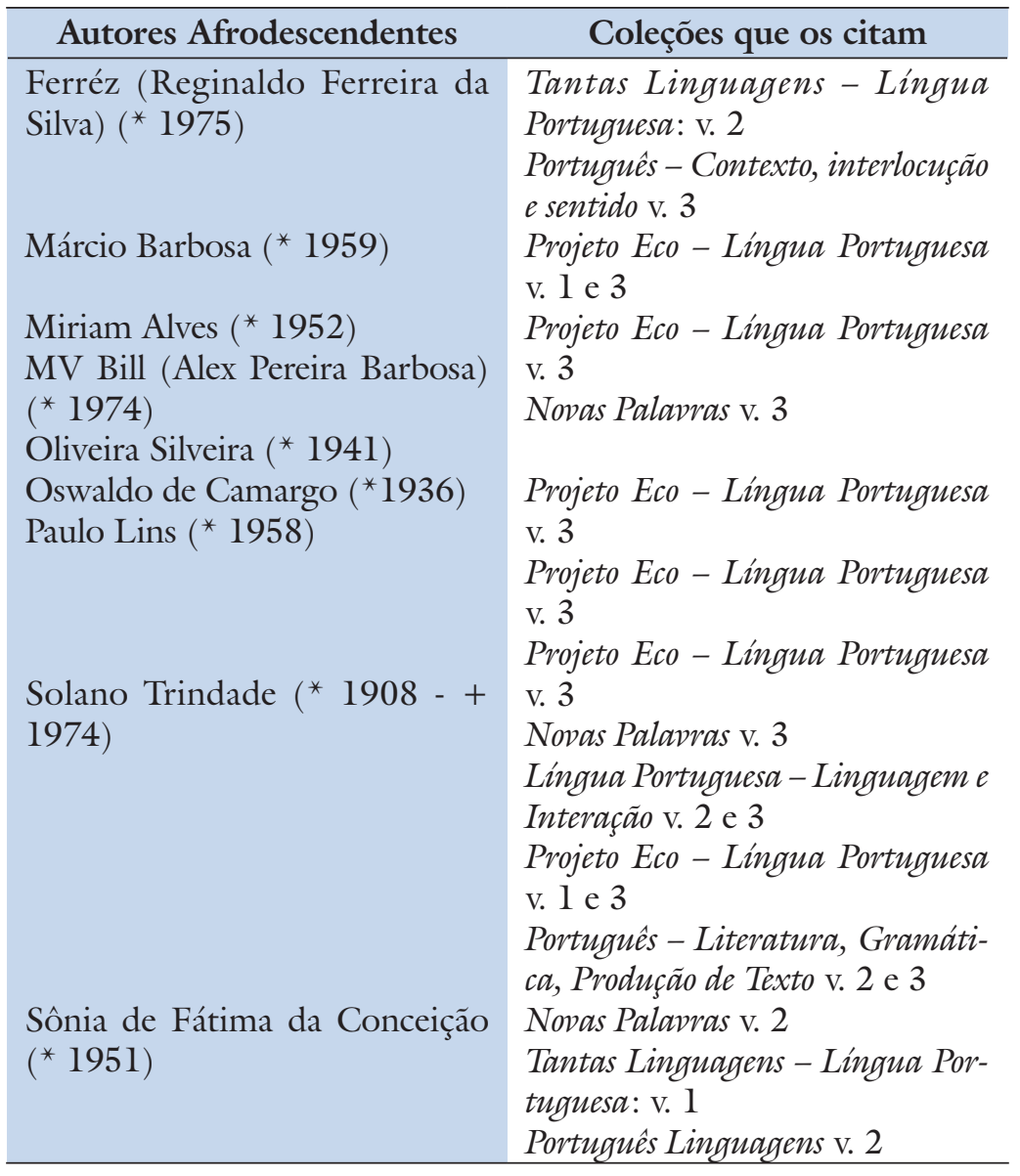

O número de coleções que referenciam tais autores cresce substancialmente, 7, das 10 coleções analisadas, fazem menção a, pelo menos, um desses escritores. Novamente, a coleção que se destaca é Projeto Eco - Língua Portuguesa (menciona 6 autores), seguida por Novas Palavras (menção a 4 autores). A maioria das coleções referencia 2 autores. O destaque negativo é das coleções Viva Português (Editora Ática), Linguagem em Movimento 
(Editora FTD) e Português: Língua e Cultura (Base Editorial), as quais não citam nenhum escritor afrodescendente contemporâneo.

O escritor mais referenciado é o poeta Solano Trindade, seguido pelos prosadores Paulo Lins e Carolina Maria de Jesus. Os autores mais jovens, no entanto - como Paulo Lins, Ferréz, MV Bill e Allan da Rosa -, são tratados mais como representantes da cultura de periferia.

A quarta e última categoria abrange autores não afrodescendentes cuja obra apresenta temática relativa à identidade e história afrobrasileiras. Essa produção será verificada e analisada posteriormente.

Se a presença da literatura afro-brasileira deixa a desejar, em compensação, o levantamento revela um avanço da presença das literaturas africanas de língua portuguesa. Todas as coleções, em maior ou menor grau, as abordam, sobretudo no terceiro volume, o qual é destinado ao estudo da produção literária contemporânea. No caso das literaturas africanas, os prosadores recebem mais destaque que os poetas, sendo os mais citados Mia Couto (Moçambique), Luandino Vieira e Pepetela (Angola).

O destaque positivo entre as coleções analisadas até o momento é a Coleção Projeto Eco - Lingua Portuguesa, a qual, desde o primeiro volume, traz fartas informações sobre as literaturas africanas de língua portuguesa. Esta abordagem diferenciada é, inclusive, salientada na resenha sobre a coleção presente no Guia de livros didáticos: "A abordagem da literatura leva o aluno a perceber as peculiaridades do texto literário, bem como estimula a leitura de produções de diferentes épocas e regiões, inclusive de Portugal, Angola, Moçambique, Cabo Verde, São Tomé e Príncipe” (2011, p. 57). Também é a única coleção a destacar os Cadernos Negros, uma das publicações pioneiras de literatura afro-brasileira, trazendo poemas de participantes do grupo Quilombhoje, como Cuti, Oswaldo de Camargo e Miriam Alves. 


\section{Conclusão}

Os resultados mostram que a produção literária afrobrasileira é muito pouco contemplada nos livros didáticos destinados ao Ensino Médio. É, inclusive, ignorada por algumas coleções, como, por exemplo, a coleção Viva Português, a qual, sendo primeira edição, já poderia ter sido elaborada levando em conta as determinações da Lei 10.639/2003. Tal cenário pode prejudicar a aplicação da Lei citada em sala de aula, já que o livro didático constitui um importante subsídio para o professor, seja no planejamento de atividades, seja como fonte atualizada dos rumos das pesquisas acadêmicas (este último aspecto é mais forte no caso de professores afastados da esfera universitária ou de grandes centros).

Nas demais coleções analisadas, é dado maior destaque à poesia afro-brasileira do que à prosa, sendo Solano Trindade e Luís Gama, depois de Cruz e Sousa e Gonçalves Dias, os poetas mais citados. Outro aspecto que pode ser observado é a preocupação em salientar a produção de autores afrodescendentes canônicos. Entre os prosadores, destacam-se Machado de Assis e Lima Barreto, já os autores contemporâneos mais citados são Paulo Lins e Carolina Maria de Jesus.

Em contrapartida à tímida presença da literatura afrobrasileira nos livros didáticos de Ensino Médio, percebe-se um aumento no espaço destinado às literaturas africanas de expressão portuguesa.

\section{Referências}

APPIAH, Kwame A. Na casa de meu pai: a África na filosofia da cultura. 2. ed. Rio de Janeiro: Contraponto, 2007.

BAUER, Martin W.; GASKELL, George. Pesquisa qualitativa com texto, imagem e som: um manual prático. 7. ed. Petrópolis: Vozes, 2008. 
BERND, Zilá. Literatura negra brasileira: racismo e defesa de direitos humanos. In: Revista Letras. Literatura, violência e direitos humanos, Santa Maria, n. 16, p. 91-102, jan./jun. 1998.

BHABHA, Homi K. O local da cultura. Belo Horizonte: UFMG, 1999.

BRASIL. Lei 10.639, de 9 de janeiro de 2003. Dispõe sobre obrigatoriedade do ensino de História e Cultura Afro-Brasileira nos estabelecimentos de ensino fundamental e médio, oficiais e particulares. In: PRESIDÊNCIA DA REPÚBLICA, CASA CIVIL. Disponível em: <www.planalto.gov.br/ ccivil_03/Leis/.../L10.639.htm>. Acesso em: 27 out. 2010.

DUARTE, Eduardo de A. Literatura afro-brasileira: um conceito em construção. Literafro, Belo Horizonte, p. 1-10. Disponível em: <www. letras.ufmg.br/literafro/ afrodescendenciaseduardo.pdf $>$. Acesso em: 25 nov. 2010.

MINISTÉRIO DA EDUCAÇÃO. Parâmetros curriculares nacionais: bases legais. Brasília: Ministério da Educação, 1999.

MINISTÉRIO DA EDUCAÇÃO. Secretaria de Educação Básica. Guia de livros didáticos: PNLD 2012 - Língua Portuguesa. Brasília: Ministério da Educação, Secretaria da Educação Básica, 2011. Disponível em: $<$ http://www.abrale.com.br/Guia\%20PNLD\%202012\%20Lingua\%20 Portuguesa.pdf $>$. Acesso em: 18 maio 2011.

MUNANGA, Kabengele. Construção da identidade negra no contexto da globalização. In: DELGADO, Ignacio G. et al. (Orgs.). Vozes (além) da África: tópicos sobre identidade negra, literatura e história africanas. Juiz de Fora: UFJF, 2006. p. 19-41.

SILVA, Tomaz T. da. Documentos de identidade: introdução às teorias de currículo. 2. ed. Belo Horizonte: Autêntica, 2005.

SOUZA, Florentina; LIMA, Maria Nazaré (Orgs.). Literatura afrobrasileira. Salvador: Centro de Estudos Afro-Orientais; Brasília: Fundação Cultural Palmares, 2006. 